\section{ADULT CARDIAC}

Chinese Surgeons International Training ProgramSponsored by Medtronic

Supports surgeons for training at a host institution in North America to obtain skills in valve repair, MICS CABG, TAVR and aortic surgery.

James L. Cox Fellowship in Atrial Fibrillation Surgery-Sponsored by AtriCure Inc.

Affords newly graduated cardiothoracic surgeons the opportunity to improve their atrial fibrillation techniques at a host institution.

\section{THORACIC}

Thoracic Surgical Robotics Fellowship-Sponsored by Intuitive Surgical

Familiarizes North American general thoracic fellows and their attending surgeons with the da Vinci robotics system during advanced training. Awardees who complete the fellowship are eligible to participate in the Advanced Lobectomy Course.

Thoracic Surgery Training Fellowship-Sponsored by Ethicon China

Offers young surgeons from China the opportunity to obtain advanced thoracic surgery skills at North American institutions.

\section{MULTI-SPECIALTY}

Japanese Association for Thoracic Surgery Fellowship-Sponsored by Medtronic

Engages Japanese cardiothoracic surgeons in an interactive educational opportunity to observe and converse with specialists in the treatment of heart valve disease or advanced minimally invasive thoracic surgery at select host institutions in North America.

\section{Summer Intern Scholarship-Supported by Scanlan}

Provides first- and second-year medical students with an eight-week summer internship in an AATS member's cardiothoracic surgery department.

\section{Research Scholarship}

Supports North American surgeons with a two-year grant of $\$ 80,000$ each year to pursue research, training, and clinical experience.

\section{Surgical Investigator Program}

Provides up to $\$ 50,000$ annually to support innovative clinical or translational research by young cardiothoracic surgeons for up to two years.

*Please note that this year's fall award timeline may be impacted by COVID-19.

\section{The Western Thoracic Surgical} Association

\section{Save the Date}

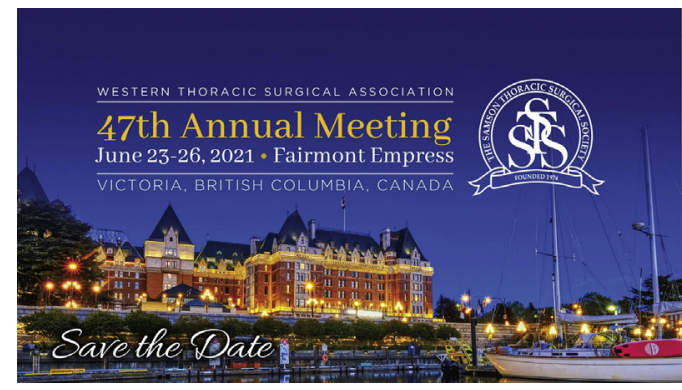

\section{WTSA 47th Annual Meeting}

June 23-26, 2021

Fairmont Empress

Victoria, BC, Canada

\section{Applications for WTSA Membership}

The WTSA is now accepting Applications for Membership online for Active as well as Candidate membership status for the 2021 membership cycle. Visit the WTSA Web site at www.westernthoracic.org to read the complete membership eligibility requirements and to initiate an online application.

\section{Active Member}

$\$ 375$ annually, plus $\$ 50$ initiation fee

Applicant must meet all membership criteria, including but not limited to:

- Reside within or have completed a cardiothoracic residency training program within the geographic limits of the Association.

- Have been engaged in the practice of thoracic and cardiovascular surgery for at least three years following completion of postgraduate training. If a candidate completed his/her thoracic surgical residency or a one-year clinical fellowship in an institution within the geographic limits of the Association, such completion may count toward one of the three years of practice.

- Have a full and unrestricted license to practice medicine in his or her respective state or province, and have a current appointment on the surgical staff 
of a hospital with no reportable action pending which could adversely affect such applicant's staff privileges at any hospital.

\section{Candidate Member}

$\$ 100$ annually

Applicant must meet all membership criteria, including but not limited to:

- Be matched or enrolled in either a cardiothoracic surgery education program accredited by the Residency Review Committee for Thoracic Surgery under the authority of the ACGME or a program approved for cardiothoracic surgery education by the Royal College of Surgeons of Canada-or their equivalency-from within the Association's geographic limits. Individuals who have completed their education in one of the above programs but do not yet meet all of the criteria for Active membership also are eligible to apply for Candidate membership. Individuals who trained outside the Association's geographic limits who are now residing within the Association's boundaries but do not yet have three years in practice may also apply for Candidate membership.

An application must include the following uploads: a photo, a complete curriculum vitae with bibliography, and, for Active applicants, the 3 most significant articles that $\mathrm{s} / \mathrm{he}$ personally wrote. The application must be completed and submitted online by March 1, 2021, and all support letter(s) (three for Active applicants, one for Candidates) uploaded by that applicant's sponsor(s) by March 31, 2021, in order for the applicant to be considered for election to membership at the 2021 Annual Meeting.

\section{The American Board of Thoracic Surgery}

\section{ABTS Announcement}

American Board of Thoracic Surgery
The American Board of Thoracic Surgery's Maintenance of Certification program was adopted 9 years ago. Since that time, there has been a continuous evaluation in the Board's thinking about the overall process, based upon internal discussions and input from our Diplomates.

These inputs resulted in our decision to migrate from a purely knowledge-based multiple-choice exam, using a Pearson Testing Center, to a Mastery Learning Process, using a SESATS format. Diplomates, enrolled in the 10-year MOC process, will fulfill their Part III requirement by completion of a home or office-based learning exam, following the instructions on the ABTS Web site.

There are 100 SESATS questions (primarily taken from SESATS XI), based on your specialty designation (Adult Cardiac, General Thoracic, Cardiothoracic, and Congenital), that you will need to work through as instructed. The exam will now be modular and tailored to your practice-for example, if your practice is $100 \%$ adult cardiac, you will only have adult cardiac and critical care questions. You will be able to take the 100-question exam anytime during the months of September and October. For those Diplomates who have used SESATS in the past, the process of working through the questions is the same. For those who are not familiar with SESATS, it might be beneficial to purchase and download SESATS and work through the specialty-specific module. This preparation will give you familiarity with the process. While SESATS may be helpful preparation, it is not required.

The goal of this exam is to provide a learning opportunity using judgement and decision making as well as knowledge. The Board and MOC Committee believe that reading the critique is key to the learning process using SESATS. The Board sincerely hopes that this new MOC Exam format that promotes life-long learning is viewed favorably by our Diplomates.

Everyone at the ABTS thanks you for embracing the primary principle of MOC-life-long learning, which is consistent with our obligation to the public trust.

\section{ABTS Requirements for the 10-Year Milestone for Maintenance of Certification}

Diplomates of the American Board of Thoracic Surgery (ABTS) who plan to participate in the 10-Year Milestone for the Maintenance of Certification (MOC) process as Certified-Active must hold a currently valid, full, and unrestricted license to practice medicine. Diplomates must have privileges at a hospital(s) accredited by the JCAHO or other institutions judged acceptable by the Board. Diplomates must also submit letter(s) of reference documenting their level of clinical activity and stature within the surgical community from the VP of Medical Affairs and one other responsible member on staff at their principal hospital. In addition, a valid ABTS certificate is an absolute requirement for entrance into the MOC process. Details on how to renew a lapsed certificate can be found on the Board's Web site at www.abts.org.

The CME requirements are 150 Category I credits over a five-year period. At least half of these CME hours need 